\title{
¿Autonomía educativa o interculturalidad? La educación alternativa entre los pueblos originarios de Chiapas, México
}

Educational Autonomy or Interculturality? Alternative Education in the Indigenous People of Chiapas, Mexico

Autonomia educativa ou interculturalidade? A educação alternativa entre os povos originários de Chiapas, México

\section{Efrén Orozco-López* (iD orcid.org/0000-0002-1686-8184}

Artículo de investigación

Revista Colombiana de Educación, N. 74. Primer semestre de 2018, Bogotá, Colombia.

Para citar este artículo: Orozco, E. (2018). ¿Autonomía educativa o interculturalidad? La educación alternativa entre los pueblos originarios de Chiapas, México. Revista Colombiana de Educación, (74), 37-61.

\section{(c) $\underset{\mathrm{BY}}{(\mathrm{i})}(\mathrm{NC}$}

Recibido: 10/02/2016

Evaluado: 10/07/2017

* $\quad$ Doctor en Ciencias Sociales y Humanísticas. Investigador en estancia postdoctoral en el Ciesas Unidad Pacifico Sur. Oaxaca, México. Correo electrónico: Iopez_efren@hotmail.com 


\title{
Resumen
}

Este artículo reflexiona sobre la pertinencia de la educación intercultural en contextos en donde se busca construir autonomía educativa. Con la emergencia del Ejército Zapatista de Liberación Nacional (EZLN) en las montañas del sureste mexicano, comunidades en lucha por sus derechos a la autonomía y la libre determinación y en resistencia a programas asistenciales impuestos desde las instancias oficiales fomentan la autonomía educativa desarrollando y consolidando procesos de educación alternativos al modelo de educación intercultural implementado por la Secretaría de Educación Pública Mexicana. Producto de un trabajo de campo antropológico realizado durante aproximadamente 10 años, en acompañamiento a una organización en resistencia, este texto expone desfases e inconsistencias existentes entre el discurso educativo intercultural de la Secretaría de Educación Pública de México (SEP) y la concepción de la educación alternativa y/o autónoma en comunidades de los Altos de Chiapas.

\section{Palabras clave}

autonomía; Iucha; resistencia; indígenas, intercultural

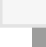

\section{Keywords}

autonomy; struggle; resistance; indigenous people; intercultural

\begin{abstract}
This paper is a reflection on the relevance of intercultural education in contexts where educational autonomy is sought. With the emergence of the Zapatista Army of National Liberation (EZLN) in the mountains of southeastern Mexico, the communities fighting for their rights to autonomy and self-determination and against programs imposed by the authorities foster educational autonomy by developing and consolidating alternative education processes to the intercultural education model implemented by the Mexican Secretariat of Public Education. The product of an anthropological field work carried out for approximately 10 years with the support of a resistance organization, this text exposes the existing gaps and inconsistencies between the intercultural educational discourse of the Mexican Secretariat of Public Education (SEP) and the conception of alternative and/or autonomous education in the communities of Altos de Chiapas.
\end{abstract}

\section{Resumo}

Este artigo reflete sobre a pertinência da educação intercultural em contextos onde se busca construir autonomia educativa. Com a emergência do Exército Zapatista de Liberação Nacional (EZLN) nas montanhas do sudeste mexicano, comunidades em luta pelos seus direitos à autonomia e à livre determinação, e em resistência a programas assistenciais impostos desde as instâncias oficiais, fomentam a autonomia educativa desenvolvendo e consolidando processos de educação alternativos ao modelo de educação intercultural implementado pela Secretaria de Educação Pública Mexicana (SEP). Produto de um trabalho de campo antropológico realizado durante aproximadamente 10 anos, em acompanhamento a uma organização em resistência, este texto expõe desfases e inconsistências existente entre o discurso educativo intercultural da Secretaria de Educação Pública Mexicana e a concepção da educação alternativa ou autónoma em comunidades dos Altos de Chiapas 


\section{Planteamiento del problema}

A inicios de abril del 2013, la Secretaría de Educación Pública (SEP) del Estado mexicano circuló el comunicado 047, documento en el que se informó a la nación sobre las modificaciones en la evaluación de la educación básica. En esta nueva normativa, se planteó la realización de una evaluación integrada entre los niveles educativos de preescolar, primaria y secundaria, lo que implicaba la eliminación de certificados por niveles educativos y la emisión de un solo certificado para la educación básica. En los nuevos reglamentos también se precisó que la acreditación del primero, segundo y tercer ciclo de primaria se daría de manera automática, es decir, se obtendrán "solo con cursar los grados", y al final de los estudios de educación básica (preescolar, primaria y secundaria) los niños y las niñas obtendrían un certificado.

Los nuevos estatutos elaborados por las autoridades educativas de la SEP generaron gran confusión y desánimo entre pobladores de diversas comunidades del municipio de Chenalhó en la región Altos del estado de Chiapas. El desánimo y confusión se debió, principalmente, a que la nueva disposición oficial fue entendida por muchos pobladores como "un alargamiento del proceso educativo de sus hijos e hijas", ya que el certificado de estudios que para ellos "vale" y es importante ya no sería entregado al término de la primaria, sino al concluir la secundaria.

Estos cambios desalentaron a numerosas familias tsotsiles, ya que la conclusión de la educación primaria significa el término de un ciclo importante para los niños/jóvenes indígenas. La educación primaria representa el mayor nivel educativo al que sus hijos e hijas pueden aspirar por su precaria situación económica y las necesidades de sustento de las familias. El hecho de extender el periodo de escolarización hasta la educación secundaria implica para muchas familias la salida de sus hijos a otras comunidades, e incluso a otros municipios o ciudades. El salir de la comunidad para estudiar genera variados gastos como traslados y renta de habitación, el pago de alimentación y útiles escolares, gastos que la gran mayoría de las familias no pueden asumir.

El hecho de pensar que la obtención del certificado "se ha alargado", junto con las limitaciones económicas de las familias indígenas —aun entre aquellos que son beneficiados con el programa federal de transferencias condicionadas Prospera-, ha representado el replanteamiento de sus aspiraciones educativas ${ }^{1}$ (Sacristán, 2013). Tal reconfiguración de horizontes se enmarca en un complejo contexto socio-político regional.

1 José Gimeno Sacristán, ha realizado una reflexión relevante mostrando la tensión entre las modificaciones ocurridas en los sistemas educativos, flexibilizados y centrados en las competencias que aspiran la competitividad e internacionalización. Analiza el desfase de estas premisas, frente a las aspiraciones de movilidad social, justicia y democracia, valores convertidos en ideologías que aun construyen importantes colectivos sociales. 
En la geografía política de Chiapas, el contexto del municipio de Chenalhó es particularmente relevante debido a que conviven en él diversas formas de organización socio-política (Freyermuth, 2003; De la Garza, 2007; Orozco, 2014). En primera instancia, conviven los "usos y costumbres", es decir, formas tradicionales de organización con las normatividades gubernamentales. También existen nuevos procesos de organización socio-política al margen de la influencia gubernamental, como son los procesos autonómicos del Ejército Zapatista de Liberación Nacional (EZLN) que comenzaron a desarrollarse desde 1996, y los procesos organizativos construidos por la Organización Sociedad Civil Las Abejas, que comenzaron a estructurarse desde 1997 a raíz de la masacre de Acteal.

Un aspecto central en los procesos organizativos y políticos, tanto de la Organización Sociedad Civil Las Abejas como del ezLn son sus proyectos de educación, propuestas diseñadas e implementadas por agentes educativos nativos de las comunidades. Un planteamiento formulado por los indígenas tsotsiles es que sus proyectos responden, por una parte, a las necesidades formativas de los niños/jóvenes (saberes social y culturalmente relevantes) y son armónicos con los proyectos políticos de las organizaciones que les dan origen. Se ha afirmado que los proyectos educativos fortalecen de manera significativa la construcción de la autonomía de los pueblos originarios (Gutiérrez, 2005, Baronnet, 2009, Bermúdez y Orozco, 2014).

En la reconfiguración del campo de la educación indígena en Chiapas, los pueblos originarios se han apropiado de elementos de una agenda internacional para los pueblos indígenas, la autonomía hasta ahora alcanzada se nutre de los discursos emanados por el convenio 169 de la Organización Internacional del Trabajo², y por la Declaración de las Naciones Unidas sobre los Derechos de los Pueblos Indígenas ${ }^{3}$, acuerdos internacionales que el Estado mexicano ha ratificado y que los pueblos indígenas de Chiapas han hecho suyos en la práctica.

Desde hace varias décadas, estos procesos educativos se han convertido en alternativas reales al modelo educativo hegemónico diseñado e implementado por el Estado a través de la Secretaría de Educación Pública y la Coordinación de Educación Intercultural Bilingüe creada en el año 2001 por el Gobierno mexicano. En este escenario, los procesos educativos que se generan al margen o en complemento a los programas educativos propuestos por las instancias de educación oficial se han convertido en opciones muy puntuales para los hijos e hijas de muchos padres de familia tsotsiles que han comenzado a poner en tela de juicio el valor de la

2 Documento disponible en la liga: http://www.cdi.gob.mx/transparencia/convenio169_oit.pdf

3 Documento disponible en la liga: http://www.un.org/esa/socdev/unpfii/documents/DRIPS_es.pdf 
educación ofertada por las instancias gubernamentales, debido a que, como ellos han señalado, ${ }^{4}$ "no responden a las necesidades y/o exigencias de las propias comunidades".

Las recientes reformas educativas, aprobadas desde el año 2013, han generado una reconfiguración del campo de la educación autónoma/alternativa/independiente a las instituciones oficiales del Estado en Chiapas. La emergencia de nuevos actores, intereses y propuestas son procesos importantes para el análisis, y su acompañamiento es de vital importancia para la reconfiguración de políticas educativas sensibles a las necesidades, sentires y objetivos de los pueblos originarios.

Sin embargo, las reformas educativas hasta ahora realizadas refuerzan la centralidad del Estado en la administración del currículum, la formación y certificación de los docentes (Bermúdez y Orozco, 2014). Asimismo, los márgenes de negociación/interacción con el Estado se vuelven cada vez más estrechos, ya que, por una parte, la política de centralización educativa ejerce presiones sobre los sujetos, y por otra, los actores muestran una mayor conciencia política y se proponen la autonomía educativa. Estos flujos contrapuestos de intereses y necesidades muestra las tensiones que este campo experimenta.

El verticalismo institucional también ha derivado en intensas protestas de los profesores afines a la Coordinadora Nacional de Trabajadores de la Educación (CNTE), cuyos militantes han colapsado varías entidades del país como Oaxaca, Chiapas, Guerrero y Michoacan a través de marchas, protestas y bloqueos. Los mismos profesores del sistema cuestionan la implementación de una evaluación única para todo el profesorado, una evaluación sin pertinencia cultural y social. Esta reforma refuerza el centralismo del Estado en el diseño del currículo y desatiende la precariedad en la que funciona un número importante de escuelas en todo el país.

\section{¿Autonomía educativa o interculturalidad?}

Las luchas sostenidas por los pueblos originarios en Latinoamérica han permitido la emergencia de una mezcla de discursos autonómicos, emancipatorios e interculturales.

La interculturalidad surgió como una opción etico-política ante la imposición, y a la vez el fracaso, de un modelo de nación fundamentalmente sustentado en la homogeneización lingüística. La propuesta emanada de Emilio Monsonyi a inicios de los noventa en Venezuela (López, 2009)

4 Lo hasta aquí expuesto como referencias a los señalamientos de los pobladores indígenas se nutre de los variados espacios de intercambio y reflexión con los integrantes de la sociedad civil Las Abejas, organización con la que colaboro desde hace cerca de 10 años. 
representó un discurso de resistencia y búsqueda de autonomía frente a la castellanización y homogeneización cultural vivida en Latinoamérica y se vislumbró como una apuesta para la educación.

Las múltiples apropiaciones discursivas y pragmáticas de la educación intercultural han derivado en una gama variada de corrientes y enfoques, ya sea por iniciativa de los pueblos originarios o del ámbito gubernamental. La interculturalidad se ha incorporado a la retórica jurídica o política de 18 países de la región latinoamericana (López, 2009). Destacan los modelos implementados por organismos internacionales como la UNESCO que propone una educación para todos, algunas otras cercanas a la educación popular y la pedagogía crítica han planteado como temas centrales la dimensión política y cultural de los pueblos originarios.

En años recientes, de cara a la colonialidad del poder y el saber, la educación intercultural de-colonial emerge como una apuesta para el reconocimiento de derechos, la construcción de un modelo de desarrollo propio y un reposicionamiento de los conocimientos indígenas (Castillo y Guido, 2015). Como apuesta política, cuestiona la reproducción de relaciones desiguales entre pueblos originarios y mestizos impuestas por el sistema de dominación colonial (Walsh, 2009).

En el devenir de la educación intercultural como apuesta política, diseño educativo o modelo de desarrollo societal, la noción ha enfrentado el embate de los Gobiernos nacionales y organismos internacionales, quienes han alterado su sentido original y lo han convertido en un concepto distanciado de la lucha contra la hegemonía, generando nociones y prácticas que se observan como simbióticas al sistema neoliberal (Muñoz, 2008).

En el caso mexicano, si bien en sus inicios el concepto educación intercultural es retomado por intelectuales indios nutridos del debate latinoamericano, al paso del tiempo, la educación intercultural derivó en una noción llamada funcional que perdió todo sentido político y se centró en aspectos de tolerancia, convivencia y respeto entre pueblos indígenas y la sociedad nacional mestiza. En México, la interculturalidad combina nociones de empoderamiento indígena, igualdad de oportunidades y de convivencia pacífica intercultural para todos (Dietz y Mateos, 2011).

Al paso de los años, las evidencias muestran que la apuesta por una educación intercultural como política gubernamental no ha tenido la intención de abordar problemáticas estructurales de desigualdad entre los pueblos indígenas y la mayoría mestiza ni tampoco busca menguar las desigualdades existentes entre grupos étnicos.

La educación intercultural en México se enuncia como una propuesta planteada para "todos," pero que ha sido exclusiva para los pueblos originarios, quienes son escolarizados en los niveles de educación preescolar y primaria a través de un modelo de educación intercultural bilingüe 
diseñado y centralizado por el Gobierno federal, que no ha erradicado las visiones castellanizadoras e integracionistas heredadas por la visión de modernización liberal.

El fracaso de este modelo de educación se hace palpable cuando la infancia que asiste a estas escuelas obtiene los menores indicadores de logro académico y trunca sus estudios a edad temprana. Los casos de movilidad social y reconocimiento social y cultural a través de la escolarización son escasos.

Existen autores que plantean que las políticas de interculturalidad en México están destinadas al fracaso, si se siguen viendo como formulas para llegar automáticamente al respeto y la tolerancia, enfocadas de lleno en tratar de dar soluciones al "problema de la diversidad", más que en buscar soluciones al problema de la desigualdad entre grupos sociales (Bensasson, 2013). Si la interculturalidad se ve como un mecanismo para cumplir con los requerimientos de instancias internacionales, y no como un medio para conocer y compartir propuestas educativas autogestivas diseñadas y aplicadas por comunidades indígenas, como por ejemplo el EZLN o la Organización Sociedad Civil Las Abejas de Acteal, los intentos de interculturalidad seguirán quedándose en buenos deseos.

También se ha establecido que la interculturalidad no puede ser interpretada si no se contemplan las relaciones históricas de dominación de los actores sociales que le dan sentido, tampoco si no se generan las herramientas necesarias para lograr revertir prácticas de dominio por situaciones de salvaguarda de la dignidad, cuidado del respeto a formas distintas de hacer y pensar, y emancipación de una colonización del conocimiento fundamentada en la idea de progreso y modernidad (Medina, 2009).

Hay quienes plantean que el debate sobre la interculturalidad debe centrarse en el campo epistemológico a partir de un cuestionamiento a la universalidad del conocimiento y superar los márgenes estrechos en los que se inscribe al pensamiento indígena, al catalogarlo como etnoconocimiento, categoría establecida desde el pensamiento occidental (Pérez y Argueta, 2011). En este sentido, se plantea ver más allá de procesos y políticas públicas interculturales o etnicistas y se insta a tender a la ambiciosa tarea de la refundación de los Estados a partir de parámetros como el respeto a los derechos humanos y dejar de priorizar la lógica económica sobre cualquier otro rubro, lo cual implica resolver problemas estructurales.

Para lograr superar paradigmas universalistas y problemas estructurales se propone dejar atrás eufemismos que inmovilizan a la interculturalidad a partir de discursos vacíos, y atacar de raíz prácticas racistas aún existentes en nuestra sociedad, que responden a la permanencia de una desigualdad política, económica y cultural. En la práctica, esta desigualdad se refleja en la negación de la identidad, en la deserción escolar y en el desprecio hacia las sociedades indígenas (Martínez, 2015). 
Con la emergencia de los movimientos insurgentes e indígenas en la nación mexicana, muchos de los pueblos originarios en resistencia han sostenido un rechazo a la noción de interculturalidad maquilada por el Gobierno mexicano y han optado por situar sus iniciativas educativas en el campo de la educación alternativa, independiente, comunal o autónoma, a distancia de la postura intercultural.

\section{Marco conceptual de la autonomía}

Es importante precisar el marco conceptual en el cual se puede definir la autonomía, debido a que puede confundirse con lucha y resistencia indígena y con usos y costumbres o sistemas normativos internos. Si bien la lucha y resistencia indígena pueden tener como efecto la autonomía, no todas las luchas indígenas decantan en procesos autonómicos, no necesariamente es su objetivo. Los usos y costumbres o sistemas normativos internos son parte de los procesos autonómicos, aunque también pueden llegar a coexistir con sistemas institucionales de gobierno, incluso pueden ocurrir hibridaciones entre estos.

Muchas luchas indígenas se han generado no necesariamente para posicionar la autonomía, en todo caso se articulan a luchas más amplias en contra del extractivismo, que es una nueva forma de despojo territorial a los pueblos originarios emanada del proceso neoliberal, y que ha sido calificada como acumulación por desposesión (Harvey, 2005). La acumulación por desposesión ha sido posible gracias a reformas estructurales de hondo calado que se han realizado en muchos países de Latinoamérica, actualmente México transita este difícil camino para las comunidades indígenas.

Los procesos autonómicos se caracterizan por tener elementos muy específicos en su fundamentación. Una identidad étnica sustentada en una territorialidad precedente a la instauración de los Estados nacionales actuales, cobijada por una espiritualidad, sacralidad y relación especial con la naturaleza (Flores López, 2007). Estos elementos son parte de la cosmovisión de los habitantes del territorio y se relacionan con referentes históricos, étnicos y territoriales identificables, como pueden ser la adscripción a un pueblo prehispánico (aimara, quechua, mapuche, maya, zapoteco), la continuidad de rituales de veneración a la madre tierra que pueden darse en los campos de cultivo, los cerros considerados sagrados, ojos de agua, cuevas y ríos, danzas y formas de organización particulares, e instituciones propias.

También es imprescindible la apropiación de un discurso legal que pueda sustentar jurídicamente la adscripción étnica, la posesión territorial y la continuidad cultural y espiritual. Para esto es necesario el conocimiento e introyección de los derechos de los pueblos contemplados en el convenio 
169 de la Organización Internacional del Trabajo (OIT) y en la Declaración de las Naciones Unidas sobre los Derechos de los Pueblos Indígenas, así como derechos contenidos en las distintas constituciones nacionales y estatales. Dos de los países en los que se ha avanzado más en este sentido es en Bolivia (Cabezas, 2011) y Ecuador (Cruz, 2013). Si bien en estos espacios se ha avanzado jurídicamente, el proceso no está exento de tensiones y aún queda mucho por resolver con lo referente a la denominada brecha de implementación (Stavenhagen, 2006).

Los procesos de autonomía y lucha y resistencia indígena han podido avanzar gracias a condiciones históricas que les favorecen. Si bien en este periodo histórico neoliberal se encuentra el peligro de la desposesión a partir de argumentos legalistas, también se abren ventanas para la lucha y la resistencia, en este caso, lo que desde las ciencias políticas se ha planteado como "la emergencia del Estado ampliado" (Oliver, 2009).

Algunos autores han dado definiciones muy generales de autonomía, la han definido como procesos de integración de elementos culturales diversos con potencial para la defensa y resguardo de derechos, así como para la transformación de los Estados nacionales latinoamericanos (Almeida, Rodas y Segovia, 2005).

Otros la diferencian de la soberanía, al establecer que la autonomía está sujeta a normas superiores, mientras que la soberanía no, en todo caso, se plantea que la autonomía pretende respeto a formas de hacer diferenciadas dentro de una estructura política definida, es considerada como un pacto entre iguales (Estado-pueblos originarios) no un privilegio concedido en una lógica horizontal, esto debido a la anterioridad de los pueblos frente a la creación de los Estados nacionales (Soriano, 2013).

Desde otra perspectiva, la autonomía de los pueblos originarios en Latinoamérica es interpretada como un proceso que cruza y trasciende todo tipo de reconocimientos legales locales, nacionales e internacionales, para situarse como un proceso de negociación en contextos y espacios particulares. La negociación se fundamenta en la interacción y confrontación de diversos actores e intereses, lo que lleva a momentos de reconocimiento y/o desconocimiento de los derechos indígenas, pero particularmente de sus territorios ancestrales (Ulloa, 2010).

También se ha planteado a la autonomía como una herramienta para poder consolidar la interculturalidad; como el punto de partida para poder lograr un verdadero diálogo intercultural, más allá de sus versiones abstractas de respeto y tolerancia; como un mecanismo de representación que poco a poco logre contrapeso a las visiones hegemónicas y posicione "políticas de cambio estructural y políticas redistributivas que ataquen las causas de la desigualdad entre los grupos culturales y entre las regiones donde estos se ubican" (Cruz, 2013, p. 66).

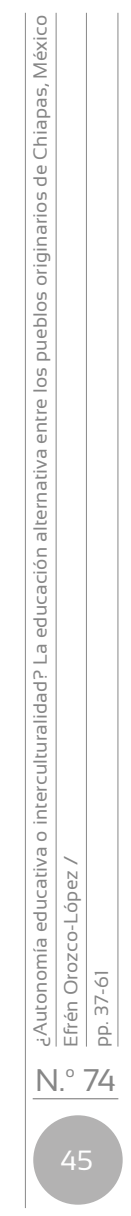


Para el caso mexicano, se ha planteado que la autonomía se ha convertido en las últimas décadas en un proceso de construcción de espacios de paz y de recuperación de tejido social. El país se encuentra viviendo una crisis de violencia generalizada protagonizada por el crimen organizado, las empresas extractivas y el propio Estado que, en su afán por atacar a los cárteles del narcotráfico y beneficiar a las grandes transnacionales en su interés por explotar recursos de territorios en los que se asientan poblaciones indígenas, ha tendido a criminalizar la protesta social y las manifestaciones e intentos de construcción de autonomía (Gasparello, 2016).

Tomando en cuenta este contexto conceptual se puede argumentar que los Estados nacionales latinoamericanos actuales, desde sus fundaciones, estuvieron organizados por elites oligárquicas que definieron el rumbo político-económico de las naciones emergentes, después, la orientación adquirió matices de totalitarismo abanderado por dictaduras militares. En el caso de México, dominó el corporativismo y clientelismo del partido de Estado (Anguiano, 2010). Tanto las dictaduras militares como las acciones del partido de Estado en México asumieron el control de lo público, así, nadie que no fuera el Estado podía tener injerencia en lo político, económico e ideológico.

Después de la primera mitad del siglo xx, sobre todo en la últimas dos décadas, poco a poco fue permeando el discurso de los derechos humanos, particularmente el de los derechos indígenas, con esto también se presentó, cada vez con mayor fuerza, la lucha por la hegemonía entre los pueblos originarios y los Estados nacionales. La hegemonía debe entenderse en su acepción de "influencia", es decir, la influencia de los pueblos originarios para, a partir del discurso de sus derechos que se legitimó internacionalmente, lograr posicionar sus demandas en las constituciones nacionales, y con esto romper la tradición totalitaria de los Estados. Esta influencia tuvo efecto y durante los años 1980 y 1990, en prácticamente toda Latinoamérica, ya estaba establecido legalmente el tema de los derechos indígenas. Es a partir de los años 90, cuando muchos pueblos originarios pasan de luchar por su reconocimiento legal a la lucha por su autonomía.

En los albores del siglo xxı, aún queda mucho por realizar, si bien legalmente los pueblos originarios pueden disputar su autonomía a los Estados nacionales, en muchos casos, como en México, viejas prácticas centralistas impiden y ponen obstáculos para que se apliquen cabalmente los derechos indígenas. En un contexto de Estado ampliado donde, en teoría, lo político y lo público no son exclusividad de los Gobiernos, en la práctica, las disputas por la dirección institucional sigue estando presente a través de viejas prácticas e ideologías enquistadas. Los Estados se reconstruyen para seguir manteniendo el control, mientras que sectores de la sociedad civil, avalada en sus derechos, como el derecho a la consulta, a las candidaturas ciudadanas, a definir agendas políticas y sociales le disputan el poder al Estado. 
En este marco, muchos pueblos originarios diseñan, construyen y aplican sus proyectos de educación alternativa, disputándole al Estado el derecho a tener una educación propia, coherente con sus lógicas de vida, arraigada en conocimientos tradicionales, impregnada de una lucha histórica en contra del despojo de sus territorios, por la reivindicación cultural, social y política, por una visión distinta de desarrollo.

\section{La educación alternativa en Chiapas}

Chiapas cuenta con una larga trayectoria de procesos de educación alternativa. El levantamiento del Ejército Zapatista de Liberación Nacional en 1994 trajo una reconfiguración del contexto socio-político en el Estado. El campo educativo ofrece una visión importante respecto a los cambios que se dieron. Después de 1994, la educación oficial pasó de ser la única opción para miles de indígenas a convertirse en una más de una serie de procesos de enseñanza-aprendizaje desarrollados en el contexto chiapaneco.

En el estado de Chiapas, se ofrecen propuestas educativas alternativas de distinto cuño, existen alguna apoyadas en nociones antigubernamentales, como es el caso de las escuelas zapatistas, hasta proyectos centrados en la revalorización de los saberes indígenas y la co-construcción de saberes como las propuestas emanadas de la Unión de Maestros de la Nueva Educación para México (UNEM) y los promotores del método inductivo intercultural (MEI). La educación que se imparte en las comunidades zapatistas ha sido como un subcampo educativo que se enfrenta al campo de la educación oficial y que se encuentra vinculada al subcampo de la educación tradicional indígena existente en regiones indígenas de los Altos de Chiapas (Gómez, 2008).

Desde esta perspectiva, la educación autónoma zapatista se presenta con antagonismo frente a la educación oficial, ya que esta se pronuncia en contra del credencialismo, el corporativismo y la burocratización y aboga por su pertinencia cultural y sus fines a favor del mantenimiento y reproducción del movimiento insurgente.

Este planteamiento también responde al hecho de que la educación pública en México se ha caracterizado por ser unicurricular, implementada a partir de políticas verticales donde los destinatarios son objetos y no sujetos activos de su propio desarrollo. Esta lógica ha hecho que la escolarización de los pueblos originarios represente una ruptura con su historia, cultura y saberes y se garantice la situación de dependencia de los grupos indígenas frente al Estado. Esta situación se fortalece gracias a las políticas públicas de transferencias condicionadas y de corte asistencialista. 
La educación zapatista se ha convertido en un espacio de relaciones en el que los militantes del EZLN asumen y disputan capital cultural y político, también adquieren reconocimiento social y colaboran en la construcción y mantenimiento de su proyecto autonómico, aunque esta forma de vida no está exenta de sufrimiento y sacrificio, carencias económicas y materiales, hostigamiento por parte del Estado y sus instituciones. Entre las investigaciones que documentan estos procesos de educación autónoma destacan las de Bruno Baronnet (2009), Kathia Núñez (2005), Raúl Gutiérrez (2005) y Horacio Gómez (2008).

Otra experiencia de educación alternativa en Chiapas es la que realiza la Unión de Maestros de la Nueva Educación para México (UNEM), que nació a raíz del levantamiento zapatista de 1994. La UNEM se posiciona como una asociación de educadores críticos del sistema político y económico neoliberal y reivindica nuevas formas de democracia y ciudadanía más participativas e incluyentes. En este sentido, la UNEM entiende que la educación intercultural apuesta no solo por una decisión pedagógica, también implica la dimensión política y representa una opción que impacta las representaciones colectivas en torno a la equidad social (Sartorello, 2009).

Otro proceso de educación alternativa en el estado de Chiapas, específicamente en el municipio de Las Margaritas, es el que desarrolló la Universidad de la Montaña. La Universidad de la Montaña surgió en 1994 debido a las necesidades contextuales de aquel momento: "La ausencia de maestros debido al conflicto armado, niñas y niños sin saber leer y escribir y una educación oficial que no respondía a sus necesidades ni a sus realidades" (Misión de Guadalupe, 2005, p. 1).

La Universidad de la Montaña se erigió sobre dos pilares: el entendimiento del conocimiento como un bien universal y la utilización del conocimiento en beneficio de las comunidades y sus habitantes. Este proceso educativo es concebido como un proyecto autónomo de educación popular. La operación del proyecto educativo alternativo comenzó a cargo de promotores de educación propuestos por las propias comunidades.

A lo largo del proceso se fue definiendo y aclarando su "necesidad educativa", y la iniciativa pasó de ser una respuesta a la necesidad inmediata de leer y escribir, a formar una conciencia de "educación comunitaria", en la que hombres y mujeres, grandes y pequeños son parte del proceso. Hoy se necesita mayor capacitación para resolver los problemas de alimentación, salud, vestido, transporte, y para enfrentar el peso abrumador del neoliberalismo sobre las tradiciones, costumbres y estilos de vida comunitaria de la región. (Misión de Guadalupe, 2005, p. 1).

El impulso de iniciativas relacionadas con la autonomía educativa en Chiapas no ha terminado, durante la última década se han creado iniciativas para la formación en educación superior como el Centro de Estudios para el Desarrollo Rural (CESDER-Moxviquil) en la Ciudad de San Cristóbal de las Casas. 
Instituciones como El Colegio de la Frontera Sur (ECOsuR), el Centro de Formación de Aprendizaje para el Desarrollo Campesino e Indígena (CEFADECI), la Organización Campesina Emiliano Zapata-Coordinadora Nacional Plan de Ayala (OCEZ-CNPA), el Centro Solidario Tsomanotik, la Unión Campesina Tojtikes, Laboratorios para la Vida (LABVIDA), Sesiones de Aprendizaje de Agroecología (SADA), la Universidad Agroecológica Multicultural Emiliano Zapata (UMAEZ), la Universidad Indígena de Bachajón (UBACH), la Universidad Autónoma de Chapingo (UACH), el Grupo Chiapas de la Unión de Científicos Comprometidos con la Sociedad (UCCS), el Ejido San Cristobalito y el Comité de Cuenca del Río San Vicente desarrollan iniciativas de educación que buscan promover la soberanía alimentaria, territorial y política de los pobladores de Chiapas.

\section{La organización Sociedad Civil Las Abejas y la lucha por la autonomía educativa}

El Proyecto de Educación Alternativa Tsotsil surgió en 1997, en el marco de la guerra entre el Ejército mexicano y el EzLN. Debido a este contexto miles de indígenas fueron desplazados en distintas regiones del estado de Chiapas. En el municipio de Chenalhó, de la región Altos, destacaron tres campamentos, dos en los que se hacinaban miembros de la Organización Sociedad Civil Las Abejas (Acteal y X'oyep) y uno poblado por simpatizantes del EZLn (San Pedro Pholó).

En el escenario de los campamentos de desplazados surgió el Proyecto de Educación Alternativa Tsotsil, que en un primer momento se llamó Proyecto de Educación para Desplazados. Este proyecto educativo suplió al sistema educativo oficial y comenzó a crear sus propios lineamientos de trabajo, en esta lógica los desplazados eligieron promotores de educación (miembros de las propias comunidades) para sustituir a los profesores oficiales.

A este hecho siguió la construcción de un currículo propio. Con el tiempo el Proyecto de Educación Alternativa Tsotsil ha cambiado sus prioridades y se ha adecuado a las nuevas circunstancias socio-políticas. A partir del año 2000, el proyecto educativo dejó de formar niños y niñas y se dedicó a alfabetizar jóvenes y adultos. La metodología se fundamenta en dos ejes de trabajo: por un lado, se toman como referentes a los libros que proporciona el Instituto de Educación de Adultos (IEA), por el otro, se trabaja en un currículo propio surgido de los intereses, problemáticas y necesidades de las mismas comunidades (Orozco, 2014).

El objetivo central del proyecto educativo es la formación política de los educandos en aras del fortalecimiento de su conciencia crítica y del sentido de identidad comunitario e indígena, así como el fortalecimiento de la Organización Sociedad Civil Las Abejas. En el año 2013, representantes 
de diversas comunidades del municipio de Chenalhó se acercaron a los promotores de educación y asesores del Proyecto de Educación Alternativa Tsotsil para pedir información sobre los cambios que se estaban generando en la forma de evaluación en las escuelas oficiales.

A partir de ese momento, muchos pobladores simpatizantes de la Organización Sociedad Civil Las Abejas decidieron dejar de llevar a sus hijos e hijas a las escuelas de gobierno y pidieron a la organización que echara a andar procesos educativos alternativos que suplieran a los oficiales. En este escenario, las comunidades comenzaron a elegir a sus nuevos promotores de educación, mientras que la Organización Sociedad Civil Las Abejas pidió al Proyecto de Educación Alternativa Tsotsil su apoyo para la formación y capacitación de dichos promotores educativos.

En el año 2010, me convertí en asesor del Proyecto de Educación Alternativa Tsotsil, mi trabajo surgió a raíz de la petición de realizar una investigación doctoral sobre dicho proyecto educativo. Entre el año 2010 y el 2014, una de mis funciones fue asesorar a promotores de educación en temáticas de su interés, la formación de los alumnos y alumnas del proyecto educativo, la docencia en las propias comunidades a niños y niñas hijos e hijas de militantes de Las Abejas de Acteal. Cuando llegó la petición de los simpatizantes de la organización de echar a andar nuevos procesos educativos alternativos, los asesores y promotores de educación iniciamos el diseño de una propuesta de intervención de corte participativo en comunidad.

Así fue como, desde agosto del año 2013, se comenzaron a realizar una serie de diagnósticos con las comunidades para identificar sus inquietudes, problemáticas y necesidades. Los diagnósticos se lograron a través de la realización de varias asambleas comunitarias, en las que los pobladores analizaron su historia de lucha e identificaron sus intereses por la alfabetización. Sintetizando los datos emanados de las asambleas comunitarias, los pobladores plantearon su interés de aprender a hablar español debido a que cuando los y las jóvenes salen de sus comunidades y no manejan la lengua española son discriminados.

Su decisión de aprender matemáticas básicas surgió debido a que cuando venden sus productos como café, frijol o maíz, en muchas ocasiones son timados por no saber hacer cuentas básicas. Al aprendizaje del español y las matemáticas, los pobladores agregaron un enfático interés por que las nuevas generaciones aprendieran la historia de la lucha de los pueblos originarios, en particular la de su comunidad, también vieron como prioritario revitalizar los conocimientos de los y las ancianas, conocimientos cada vez más despreciados por las nuevas generaciones.

Es de destacar la importancia de los referentes de las necesidades educativas de las propias comunidades, debido a que este es el punto de partida para el diseño, elaboración y aplicación de materiales educativos con pertinencia. En caso de no tomarse en cuenta las circunstancias de 
la necesidad educativa, muy probablemente los ejemplos a partir de los cuales se alfabetizará y educará no necesariamente serán congruentes con las raíces de los problemas detectados, por lo cual no ofrecerán soluciones puntuales a lo que se espera por parte de las comunidades.

A partir de la información colectada en las asambleas comunitarias se comenzaron a trazar los primeros ejes de enseñanza-aprendizaje. Los promotores de educación comenzaron un proceso de formación a partir de los primeros datos obtenidos y sistematizados. Su capacitación giró en torno a aspectos como identidad indígena, raíces mayas y católicas, así como en los principales preceptos de lucha y resistencia generados por la Organización Sociedad Civil Las Abejas, la enseñanza de las matemáticas y el español.

A partir de enero de 2014, los promotores de educación de la Organización Sociedad Civil Las Abejas comenzaron a formar a niños y niñas de diversas comunidades del municipio de Chenalhó, paralelamente los promotores de educación y los asesores del Proyecto de Educación Alternativa Tsotsil hemos estado trabajando en la elaboración del currículo y los contenidos que los nuevos promotores de educación están y estarán trabajando con los educandos en las escuelas alternativas, ahora enmarcadas en el naciente Proyecto de Educación Independiente de Las Abejas de Acteal.

El Proyecto de Educación Independiente de Las Abejas de Acteal tiene una lógica muy particular. Como se explicó, los contenidos curriculares tienen su fundamento en las necesidades más sentidas de las propias comunidades, el trabajo de los asesores es convertir esas necesidades en procesos de enseñanza-aprendizaje, que son consensados con los promotores de educación, encargados de aplicarlos en las comunidades. Además de los asesores, que pueden ser tesistas, prestadores de servicio social, investigadores o simplemente voluntarios comprometidos con la organización, existen organizaciones sociales o asociaciones civiles que apoyan al Proyecto de Educación Independiente de Las Abejas de Acteal. Es el caso de la Organización Otros Mundos Chiapas, organización encargada de sistematizar, proponer y consensuar los contenidos del campo de la naturaleza con los promotores de educación.

En lo hasta ahora revisado, se destaca que las propuestas de educación alternativa son producto de un cuerpo de demandas y procesos organizativos de los pueblos indígenas, tienen distintos objetivos y reivindican demandas distintas. Sin embargo, ciertos temas las atraviesan, como la identidad étnica y política (¿quiénes somos?, ¿a dónde vamos? y ¿cómo nos relacionamos?), los cuales redefinen y discuten sus identidades frente a los modelos homogeneizadores del sistema educativo nacional. Se plantean también como preocupación su autonomía, la capacidad de decidir sobre sus procesos, y definir su historia en el presente. Algunos más incorporan preocupaciones sobre su territorio, la migración de sus pobladores y la lucha por sus derechos como colectivos. 


\section{Resistencia frente a la hegemonía de lo intercultural}

Las configuraciones educativas descritas en el punto anterior, así como las dinámicas organizativas generadas a partir de esta, se pueden insertar en el marco de la discusión teórica sobre la educación intercultural. La educación intercultural se enmarca en un proceso de reinvención del Estado que comenzó a darse desde finales del siglo xx a partir del cuestionamiento de las relaciones tradicionales entre el Estado y los pueblos originarios.

Con la propuesta de interculturalizar las relaciones socio-políticas, se intentó superar el paradigma del multiculturalismo en el que se visualizaban sociedades compuestas de grupos culturales diversos, grupos que debían ser reconocidos constitucionalmente. El paradigma de la interculturalidad trata de dar el salto del mero reconocimiento a la convivencia entre culturas.

El discurso intercultural que se sitúa en un contexto posnacionalista fue introducido por intelectuales desde universidades europeas y originalmente se planteaba como punto de partida el análisis de "la diversidad cultural, concebida como el producto de la presencia de minorías étnicas y/o culturales o del establecimiento de nuevas comunidades migrantes en el seno de las sociedades contemporáneas" (Dietz, Mateos, Jiménez y Mendoza, 2009, p. 27).

Actualmente, la principal tendencia ideológica dominante del discurso intercultural hegemónico está representada en el informe coordinado por el político francés Jacques Delors (1996), aunque también coexisten interpretaciones críticas de la interculturalidad como las de Patricia Medina (2009), Alejandro Cerda (2007) o Ruth Moya (2009).

Esta nueva tendencia ideológica ha venido a romper con una larga tradición en la que el Estado mexicano se encargaba de delinear, diseñar y aplicar políticas educativas, para pasar a un periodo en el que el Estado deja de ser forjador de políticas educativas para convertirse en administrador de lineamientos internacionales. La primera etapa de este proceso data del periodo posrevolucionario cuando se aplicó una política educativa encaminada a "mexicanizar" a través de la imposición de la lengua nacional como única, y la asimilación del indígena a la cultura nacional.

En 1934, se creó el Departamento de Educación y Cultura Indígena y en 1939 el Proyecto Tarasco en el que se implementó un método de castellanización a partir de la lengua materna. En 1948, se creó el Instituto Nacional Indigenista (INI) con el objetivo de integrar el indígena al desarrollo del país y, en 1963, la SEP creó una política de educación bilingüe. En 1978, se institucionalizó la Dirección General de Educación Indígena (DGEI), estableciendo un modelo de educación bilingüe-bicultural (Martínez, 2011). 
Las cosas comenzaron a cambiar en el año 1992, cuando México se declaró constitucionalmente como un Estado pluricultural. Este hecho acarreó una fuerte crisis en el diseño y aplicación de políticas educativas para los pueblos originarios que desembocó en la instauración de la Coordinación de Educación Intercultural Bilingüe y en la publicación de la Ley General de Derechos Lingüísticos de los Pueblos Indígenas en el año 2003.

Los lineamientos educativos que el Estado mexicano retoma y aplica a partir de las recomendaciones de la UNESCO están centrados en el respeto y la tolerancia en aras de forjar solidaridad y buena convivencia entre culturas. Una crítica recurrente a los lineamientos educativos impuestos por la UNESCO y la SEP-CGEIB es que estas instancias centran su atención en la lengua y la cultura de los pueblos originarios folklorizándolos e invisibilizando aspectos centrales en los procesos educativos nativos como son la participación comunitaria, la convivencia colectiva "bien común", y su politización, en el marco de los procesos de institucionalización de educación intercultural, como fundamento del paradigma educativo para los pueblos originarios. Además de la centralidad del Estado en la administración de recursos y apoyo a ciertas propuestas, la SEP tiende a caracterizar propuestas independientes como procesos educativos interculturales (Orozco, 2014).

Un ejemplo de ello es el Proyecto de Educación Alternativa Tsotsil, que, sin ser un proceso educativo que se asuma como "intercultural", es denominado así por las instancias oficiales, además, cuando se hace referencia a este proceso educativo alternativo se plantea que su objetivo es la revalorización de la lengua y la cultura, y se omite que su planteamiento central es la formación de una conciencia política de sus integrantes (Orozco, 2014).

Esta visión etnofágica y discursiva de la interculturalidad no es la única que existe. Las debilidades de la política intercultural hegemónica se manifiestan de manera contundente en la vida diaria de miles de indígenas, en problemas estructurales de acceso y calidad en la educación, la desatención e indiferencia hacia las comunidades por parte de las autoridades gubernamentales. A partir de esta realidad, muchos pueblos originarios optan por crear estrategias alternativas que suplan y/o complementen la propuesta unidimensional que el Estado mexicano ofrece.

Esta situación acarrea una disputa entre las instancias oficiales que mantienen la tendencia de la incorporación, asimilación y castellanización de los pueblos originarios, tomando como referente el discurso intercultural frente a la creación de instancias alternativas que pugnan por generar nuevas relaciones entre el Estado y los pueblos originarios disputando nuevas formas de estatalidad. La tensión generada entre pueblos originarios y Estado se enmarca en un escenario en el que una serie de actores de comunidades indígenas son productores de una hibridación cultural 
que reestructura las formas de organización interna de las comunidades gracias a redes urbano-rurales: "Los nuevos actores híbridos 'etnifican' sus demandas a la vez que las articulan en un nivel supralocal" (Dietz y Mateos, 2011, p. 123).

En este campo lo que se disputa es la ciudadanización de los pueblos indígenas que es abanderada a partir de la lucha por la autonomía política. Algunos elementos que sustentan la idea de autonomía son la identidad colectiva, pero sobre todo el sentido de pertenencia a una comunidad determinada que implica un sistema normativo propio que prescribe formas de organización determinadas y un prototipo de "bien vivir" (Dietz y Mateos, 2011), "lekil kuxlejal", para los tsotsiles de Chiapas. Esta forma de entender la realidad es denominada en algunos lugares como comunalismo.

En el comunalismo el fenómeno educativo tiene gran importancia ${ }^{5}$. La educación comunal retoma experiencias pedagógicas y organizativas emanadas de la reflexión de intelectuales indígenas, quienes han tomado a la comunalidad como una opción política y una respuesta a los procesos de desmantelamiento de sus comunidades. En el caso de Oaxaca, han redundado experiencias de educación autónoma (algunas validadas por el Estado), lo que implica la reinvención de lo escolar desde las necesidades locales y sobre todo se deslindan de prácticas y aparatos burocráticos de intermediación política e institucional.

La educación comunal puede circunscribirse en el espectro de la educación alternativa, desde donde se proponen variados tipos de relaciones entre el Estado y los pueblos originarios, es decir, desde una nula participación, pasando por una participación comunitaria débil, hasta una participación determinante por parte de los y las integrantes de diversas comunidades indígenas que cotidianamente construyen procesos de autonomía indígena. Existen diversos factores por los cuales la creación de instancias alternativas a las oficiales está tomando cada vez más fuerza, por ejemplo:

A nivel jurídico, los recientes cambios legislativos en cuanto a los derechos lingüísticos de los pueblos no aportan solución para el desafío político de proporcionar a todos los niños indígenas una educación en su propia lengua. Dejando aparte a cientos de miles de alumnos indígenas escolarizados en castellano, la política pública de educación bilingüe aún está lejos de responder flexiblemente a la necesidad de adaptar la enseñanza a medios extremadamente plurilingües y multiétnicos como lo son ciertas comunidades de estados como Morelos y Chiapas. (Baronnet, 2013, p. 187).

5 Uno de los autores más importantes en este tema es Benjamín Maldonado, quien ha realizado diversas propuestas sobre la educación comunal en Oaxaca, destaca su texto: Comunidad, comunalidad y colonialismo en Oaxaca (ver lista de referencias). 
La situación expuesta en la cita anterior se agrava si se toma en cuenta que la desarticulación entre el sistema de educación intercultural y bilingüe (EIB) y las necesidades formativas de los pueblos originarios se extienden a lugares como el Estado de México, Tabasco, Veracruz y Oaxaca en el sur; Jalisco y Nayarit en el occidente, y Chihuahua y Durango, en el Norte, solo por mencionar algunos estados de la república mexicana en donde existen importantes asentamientos de pueblos originarios. A los factores estructurales se agrega que las escuelas con sistemas educativos federalizados enclavadas en regiones indígenas del país, muy pocas veces utilizan como lengua de enseñanza directa las lenguas originarias, es decir, el castellano es la lengua única que se impone a los y las alumnas por igual.

El escenario planteado ha generado resistencias educativas que se enmarcan en debates teóricos muy puntuales, es el caso de la pedagogía de la liberación de Paulo Freire (1969), que cuestiona la labor de la educación escolar debido a que se encuentra planteada y diseñada para mantener los privilegios de la clase dominante. La dominación de una capa social privilegiada sobre sectores populares excluidos y empobrecidos por el sistema se presenta cuando el sistema educativo impone, a través de los programas y lineamentos oficiales valores, aspiraciones y modos de vida hegemónicos y los plantea como únicos.

En este escenario, los excluidos del sistema no solo introyectan, sino que reproducen patrones de vida muchas veces ajenos a su realidad, lo que redunda en el ajustamiento de los individuos a un sistema social injusto que se fundamenta en la desigualdad económica, política y cultural. El ajustamiento al que están sometidos grandes sectores de la sociedad provoca que el ser humano pierda su capacidad creadora y sea incapaz de entender su realidad, agotando con esto su capacidad crítica.

Ante estos hechos Freire plantea un programa educativo de corte liberador encaminado a devolverle al ser humano su agencia política, lo que da como resultado la transformación de su realidad de opresión por una conciencia de sí, es decir, de sus identidades, y de su posición en el mundo, de su lugar en el sistema con respecto a la política, la cultura y la forma de vida dominante.

Se puede argumentar que estas premisas son compartidas por muchos proyectos de educación alternativa, ya que sus procesos se fundamentan en la articulación de ejes de enseñanza-aprendizaje con la realidad de una comunidad determinada, en la valorización de conocimientos locales y en la politización de sus individuos, que se encamina a la búsqueda de la liberación económica, política y cultural. Otro enfoque teórico que abona para el análisis de los proyectos de educación alternativa es el planteado por James Scott (2000). 
Si bien Scott no trata directamente del fenómeno educativo plantea argumentos que pueden ser concomitantes con este, específicamente con la postura educativa planteada por Paulo Freire. Scott argumenta que en las estructuras de dominación prevalecen reacciones y estrategias de resistencia popular ante un discurso público hegemónico. Las imágenes emanadas por este discurso se conforman a partir del autorretrato de las élites dominantes que tienden a naturalizar y afirmar su poder, además se proyectan para lograr el convencimiento ideológico de los subordinados en aras del mantenimiento del status quo.

Tomando en cuenta los argumentos presentados, se puede plantear que el discurso educativo intercultural, entendido como discurso hegemónico y que en algunos casos busca generar contrahegemonía (Walsh, 2009), se ve limitado en la práctica pedagógica, ya que no siempre queda claro en qué momento los pueblos originarios, después de comprender su realidad de opresión participan en la transformación de su mundo. Frente a esta posición dominante, se esgrimen distintas formas de interpretar la educación y de construir modelos alternativos de educación que se adscriben a diversas corrientes, como por ejemplo la educación comunal (Maldonado, 2011), la educación autónoma, la educación independiente o la educación popular.

\section{Conclusiones}

Este artículo se enmarca en el trabajo que he realizado durante más de 10 años con la Organización Sociedad Civil Las Abejas. A lo largo de este periodo, destaco que, trabajar, sistematizar y fortalecer desde la investigación educativa a los proyectos de educación alternativa, en específico al Proyecto de Educación Alternativa Tsotsil, es de gran trascendencia debido a su aporte a la construcción de visiones diversas que abordan el fenómeno educativo. Además, se alimenta con elementos pedagógicos y políticos que aportan al enriquecimiento de contextos complejos, como es el caso de la sociedad mexicana.

También permite documentar los procesos de autonomía que se conducen desde los pueblos originarios, quienes cuentan con una larga historia de lucha y resistencia por mantener prácticas de vida cotidiana e institucional que les brindan sentidos más amplios a la teoría y la práctica de la democracia. Al desarrollar investigaciones con rigurosidad científica y comprometida con los actores, y acompañarlos en procesos de reflexión educativa, permite que las propuestas de investigación se traduzcan en resultados concretos y beneficios para los pueblos originarios.

Este tipo de proyectos de educación alternativa aportan elementos significativos para matizar, criticar y dar contenido a los discursos de la interculturalidad implementada por las instancias del Gobierno mexicano. 
En este artículo, se muestra la distancia existente entre las necesidades educativas de los pueblos originarios y sus esfuerzos por construir autonomía educativa, frente al vaciamiento político que enfrenta la Еı impartida por las instancias educativas del Gobierno mexicano.

Algunas de las apuestas implementadas por las organizaciones políticas e indígenas de Chiapas buscan construir nuevos tipos de estatalidad, los pueblos originarios no renuncian a construir una sociedad igualitaria con bases sólidas de respeto en todos los planos de la diversidad cultural, las educaciones alternativas y autónomas cuestionan las relaciones de poder, la hegemonía de las instancias gubernamentales, así como las prácticas coloniales existentes aún. También reivindican derechos territoriales y culturales que han sido subyugados.

Lo cierto es que las instancias gubernamentales encabezadas por la elite mestiza no siempre están dispuestas a ceder en los ámbitos del poder y la construcción de una nueva nación mexicana, las disputas por la hegemonía entre pueblos originarios e instancias gubernamentales revelan justamente lo que Gramsci llamaba "el Estado ampliado" y la disputa por la dirección institucional.

El diseño, elaboración, aplicación, acompañamiento y sistematización de proyectos y procesos de educación alternativa refuerzan lo que Freire generó durante muchas décadas y que tenía que ver con hacer teoría desde la práctica, valorizar el conocimiento desvalorizado por los "expertos" en la elaboración de políticas públicas, en la creación de nuevos conceptos significativos para determinados grupos sociales, que no necesariamente están en sintonía con modas académicas o marcos teóricos y conceptuales que se convierten en patrimonio de intelectuales o círculos académicos privilegiados.

En este sentido, los proyectos de educación alternativa promueven el debate alrededor de la investigación en el contexto del siglo xxI, debido a que plantean retos con respecto a la intervención del investigador en espacios de creación de conocimiento comunitario, colectivo, que a todas luces va a contracorriente de las políticas educativas que se ciñen cada vez más a parámetros individualistas, que refuerzan y gratifican el prestigio personal sobre aspectos como la transformación de la realidad y la generación de conciencia crítica, tanto en el investigador como en los sujetos que participan en los procesos de investigación. 


\section{Referencias}

Almeida, I., Rodas, N. A., y Segovia, L. O. (2005). Autonomía indígena: frente al Estado nación ya la globalización neoliberal, Quito, Ecuador Editorial Abya Yala.

Anguiano, A. (2010). El ocaso interminable. Política y sociedad en el México de los cambios rotos. México: Ed. Era.

Baronnet, B. (2013). Lenguas y participación comunitaria en la educación indígena en México. Revista de Antropología Iberoamericana, 8(2), 183-200. Recuperado de http://www.redalyc.org/ pdf/623/62329867003.pdf

Baronnet, B. (2009). Autonomía y educación indígena: las escuelas zapatistas de las cañadas de la selva lacandona de Chiapas, México (tesis doctoral). El Colegio de México, A. C., y Université Sorbonne Nouvelle. París III. Recuperado de http://www.cedoz.org/site/pdf/cedoz_886.pdf

Bensasson, L. (2013). Educación intercultural en México ¿por qué y para quién? B. Baronnet y M. Tapia (coords.), Educación e interculturalidad. Política y políticas. México: unAm/CRIM. Recuperado de: http:// www. libros. unam. mx/digital, 7.

Bermúdez, F., y Orozco, L. E. (2014). La formación del magisterio indígena y su evaluación. Una discusión necesaria en el marco de la reforma educativa 2013 (pp. 135-158). En Anuario Cesmeca 2013. MéxiCO: UNICACH. Recuperado de https://www.academia.edu/10285923/ La_formación_del_magisterio_ind\%C3\%ADgena_y_su_evaluación._Una_discusión_necesaria_en_el_marco_de_la_reforma_educativa_2013

Cabezas, S. (2011). Cartilla autonomía. Bolivia. Comité Boliviano UICN. Recuperado de https://cmsdata.iucn.org/downloads/_cartilla_autonomia.pdf

Castillo, E., y Guido, G. S. (2015). La interculturalidad: ¿Principio o fin de la utopía? Revista Colombiana de Educación, 69, 17-44. Recuperado de http://revistas.pedagogica.edu.co/index.php/RCE/article/ view/3244/2809

Cerda, A. (2007). Multiculturalidad y educación intercultural. Entre el neoindigenismo y la autonomía. Andamios, 3(6), 97-137. Recuperado de http://www.scielo.org.mx/scielo.php?script=sci_arttext\&pi$\mathrm{d}=$ S1870-00632007000100005

Cruz, E. (Enero-junio, 2013). Estado plurinacional, interculturalidad y autonomía indígena: Una reflexión sobre los casos de Bolivia y Ecuador. Revista Via iuris, 14, 55-71. Recuperado de http://www.redalyc. org/pdf/2739/273929754005.pdf 
Garza de la, A. (2007). Conflicto, etnicidad y género en la política interna de San Pedro Chenalhó, Chiapas. Sociológica, 22(63), 85-110. Recuperado de http://www.redalyc.org/articulo.oa?id=305026593005

Delors, J. (1996). La educación encierra un tesoro. España: Santillana-Unesco. Recuperado de http://www.unesco.org/education/pdf/ DELORS_S.PDF

Dietz, G., y Mateos, L. (2011). Interculturalidad y educación intercultural e México. Un análisis de los discursos nacionales e internacionales en su impacto en los modelos educativos mexicanos. México: CGelB-SEP. Recuperado de http://www.interculturalidadygenero-colsan.com. $\mathrm{mx/v4/pdf/GUNTHER \% 20DIETZ.pdf}$

Dietz, G., Mateos, L., Jiménez, Y., y Mendoza, R. (2009). Los estudios interculturales ante la diversidad cultural. Una propuesta conceptual. Revista Decisio, 24, 26-30. Recuperado de http://www.crefal.edu. $\mathrm{mx} /$ decisio/images/pdf/decisio_24/decisio24_saber4.pdf

Flores López, J. A. (2007). Autonomía indígena en Chocó. Colombia. Centro de Estudios Étnicos. Recuperado de http://pacificocolombia.org/ wp-content/uploads/2016/05/0305544001277733776.pdf

Freire, P. (1969). Educación como práctica de la libertad. Uruguay: Siglo xxı. Recuperado de http://www.educacionsalta.com.ar/files/archivos/bibliotecas/3/eccbc87e4b5ce2fe28308fd9f2a7baf3.pdf

Freyermuth, G. (2003). Las mujeres de humo: morir en Chenalhó. Género, etnia y generación, factores constitutivos del riesgo durante la maternidad,México, CIESAS.

Gasparello, G. (2016). Autonomías indígenas en México: construir la paz en contextos violentos. Quaderns-e de l'Institut Català d'Antropologia, 21(1), 81-97.

Gómez, H. (2008). Indígenas mexicanos y rebeldes. Procesos educativos y resignificación de identidades en los Altos de Chiapas (tesis doctoral). Universidad de Sevilla, Sevilla, España.

Harvey, D. (2005). El nuevo imperialismo: acumulación por desposesión. Argentina. Recuperado de http://biblioteca.clacso.edu.ar/clacso/ se/20130702120830/harvey.pdf

Gutiérrez, R. (2005). Escuela y zapatismo entre los tsotsiles: entre la asimilación y la resistencia (Tesis de maestría). Ciesas-Sureste, México.

López, E. (2009). Interculturalidad, educación y política en América Latina: perspectivas desde el sur, pistas para una investigación comprometida y dialogal. En E. López (Ed.), Interculturalidad, educación y ciudadanía en América Latina. Perspectivas latinoamericanas (pp. 129220). Bolivia: Plural-FunPROEIB. 
Martínez, E. (2011). La educación indígena e intercultural en México y sus implicaciones en la construcción de ciudadanías. Ponencia presentada en el XI Congreso Nacional de Investigación educativa. Recuperado de http://www.comie.org.mx/congreso/memoriaelectronica/v11/docs/area_12/1004.pdf

Martínez, E. (2015). La educación intercultural y bilingüe (ЕІв) en México. ¿El camino hacia la construcción de una ciudadanía democrática? Relaciones(Zamora), 36(141), 103-131.

Maldonado, B. (2011). Comunidad, colonialidad y colonialismo en Oaxaca. México: CSEIIO-Universidad de Leiden.

Medina, P. (2009). Repensar la educación intercultural en nuestras Américas. Revista Decisio, 24, 3-14. Recuperado de http://www.crefal. edu.mx/decisio/images/pdf/decisio_24/decisio24_saber1.pdf

Misión de Guadalupe (2005). La universidad de la montaña un modelo alternativo de educación, documento, Las Margaritas, Chiapas, México.

Moya, R. (2009). La interculturalidad para todos en América Latina. En E. López (Ed.), Interculturalidad, educación y ciudadanía en América Latina. Perspectivas latinoamericanas (pp. 21-56). Bolivia: Plural-FunPROEIB.

Muñoz, H. (2008). Indígenas y educación intercultural en América Latina. En C. Marras Gianna y R. Badini, Intrecci di culture. Marginalita ed egemonia in América Latina e Mediterraneo (pp. 15-34). Roma, Italia, Meltemi editore. Recuperado de https://goo.gl/h3PGmJ

Núñez, K. (2005). Socialización infantil en dos comunidades Ch'oles. Rupturas y continuidades: escuela oficial y escuela autónoma (Tesis de maestría). Ciesas-Sureste, México.

Oliver, L. (2009). El Estado ampliado en Brasil y México. México: Universidad Nacional Autónoma de México (UNAM).

Orozco, L. E. (2014). La Organización Sociedad Civil Las Abejas. Procesos de lucha, resistencia y educación indígena (Tesis doctoral). Cesmeca-unicaCH, México.

Pérez, M. L., y Argueta, A. (2011). Saberes indígenas y diálogo intercultural. Cultura y representaciones sociales, 5(10), 31-56.

Sartorello, S. (2009). Una perspectiva crítica sobre interculturalidad y educación intercultural bilingüe: el caso de la Unión de Maestros de la Nueva Educación para México (UNEM) y educadores independientes en Chiapas. Revista Latinoamericana de Educación Inclusiva, 3(2), 77-90.

Scott, C. (2000). Los dominados y el arte de la resistencia. México: Era.

Sacristán, G. (2013). En búsqueda del sentido de la educación. España: Morata. 
Schmelkes, S. (2013). Educación y pueblos indígenas: problemas de medición. Revista realidad, datos y espacio. Revista internacional de estadística y geografía, 4(1), 5-13. Recuperado de http://www.inegi. org.mx/RDE/RDE_08/Doctos/RDE_08_Art1.pdf

Soriano, M. L. (2013). El derecho a la autonomía política en los pueblos indígenas de América Latina. Nómadas, Vol. Especial: América Latina

Stavenhagen, R. (2006). Los derechos humanos y las cuestiones indígenas. Informe del Relator Especial sobre la situación de los derechos humanos y las libertades fundamentales, de los indígenas. Naciones Unidas, Consejo Económico y Social.

Ulloa, A. (2010). Reconfiguraciones conceptuales, políticas y territoriales en las demandas de autonomía de los pueblos indígenas en Colombia. Tabula Rasa, (13), 73-92.

Walsh, C. (2009). Interculturalidad crítica y educación intercultural. Ponencia presentada en el Seminario Interculturalidad y Educación Intercultural, organizado por el Instituto Internacional de Integración del Convenio Andrés Bello, La Paz. 